\title{
Analysis on the Current Situation of Residential Ventilation in China
}

\author{
$\mathrm{Ke} \mathrm{Li}$ \\ Department of Power Engineering, School of Energy, Power and Mechanical Engineering, North \\ China Electric Power University, Baoding, Hebei 071003,PR China \\ 15933932038@163.com
}

Keywords: Residential building; natural ventilation; Mechanical ventilation; Air volume

\begin{abstract}
Currently the indoor air quality (IAQ) of the public residence of the local majority is poor. And the effective total air change rate (h-1) is low. But the indoor environment just depending on natural ventilation does not satisfy the people's request to the IAQ. Therefore, it becomes more and more necessary to maintain the indoor air quality by using organized mechanical ventilation.
\end{abstract}

\section{Introduction}

The house is a place where people live every day. Fresh and clean air is the basis of people's health and quality life. Mass use of air conditioner creates a good indoor temperature and humidity environment, but it also had created many problems. For example Sick Building Syndrome and Air-sickness are common in life. The reason for this kind of disease is that the ventilation is not enough. In order to ensure a comfortable indoor temperature of modern architecture and reduce building energy dissipation, doors and windows of house are more and more tight, windows could be opened are getting smaller and smaller. It has reduced the ventilation of the houses. Indoor pollutants cannot be cleared in time and lead to serious air pollution. Therefore, ventilation is an important means to effectively improve the indoor air quality of residential buildings.

\section{Ventilation Type}

At present in China, the main ventilation mode is natural ventilation and mechanical ventilation. A large number of civil buildings relies on natural ventilation to achieve indoor ventilation. Basically, the high-rise apartment is still dependent on natural ventilation. Domestic air conditioning can only regulate indoor air temperature and humidity; most of them have no ventilation function. Common domestic residential indoor ventilation system includes hood, fan, ventilator etc. Indoor air pollution is discharged by way of a mechanical forced exhaust and the room is ventilated fully or partially.

\subsection{Natural Ventilation}

Natural ventilation is the natural way to achieve new air intake and exhaust. Generally, there are two natural ventilation mode, natural ventilation by wind pressure, natural ventilation by temperature and pressure. Temperature and pressure by the buoyancy effect is small while wind pressure is significant. The significant advantages of natural ventilation are simple, economical and no device noise.

Traditional way of life and ideas suggest us that natural ventilation is the most straightforward way to get fresh air. In fact, select the appropriate time to open the doors by fully account of indoor and outdoor temperature, air pressure, windows, ventilation can be achieved very good results. In many regions and climatic conditions, we prefer to get fresh air and natural ventilation to adjust the indoor temperature, even in urban design, general layout design, you can also take advantage of the prevailing wind direction in summer to design the right shape and form of city buildings. Thereby reducing the cooling heat load and the use of air conditioning could save energy.

\subsection{Mechanical Ventilation}

Building insulation performance good setting mechanical ventilation is necessary, mechanical ventilation can ensure air can be well controlled indoor humidity. Ensure cleanliness into the interior, while also reducing the impact of outdoor noise and pollutants. 


\subsubsection{The Principle of Residential Mechanical Ventilation}

Ventilation systems can bring plenty of fresh air to the room and dispel odor, poisonous gas and various kinds of pollution. Ventilation systems can extend the service life of building and prevent the building from mildew, especially. Ventilation systems will meet building energy efficiency code requirements; with high reliability, low-profile Long, low noise. Residential mechanical ventilation should follow certain principles. Firstly ventilation path should enable fresh air first enters the living room, bedroom and other staff activities. Secondly ventilation ensures that the use of the kitchen, bathroom and the amount of fresh air of people's daily life. Thirdly we should not only ensure the kitchen, bathroom ventilation, but also as far as possible 24 hours a day according to the preceding two principles of continuous ventilation.

\subsubsection{Mechanical Ventilation Modes and Forms}

Both send and exhaust ventilation mode: Type of ventilation system of this model include air fan coil system with fresh air independent air system, continuous kitchen exhaust (cold source or centralized residential central air-conditioning systems); residential central air-conditioning systems with new wind suction, kitchen exhaust continuous full air; indoor mechanical ventilation systems with new wind ventilators; household air conditioning ventilation system with heat recovery and so on. Only send non-exclusive ventilation modes: Ventilation systems form part of this model, such as no continuous exhaust air fan coil system, residential central air conditioning systems.

Only exhausting with no sending ventilation modes: it should belong to a more reasonable balance with self-control or a wet-type residential central air inlet mechanical ventilation system.

\section{Analysis of Traditional Residential Ventilation Methods}

\subsection{Analysis of Traditional Indoor Ventilation Methods}

In most of the residential, the living rooms and the bedrooms ventilate by natural ventilation, while the kitchens and the bathrooms ventilate by local mechanical ventilation, which will produce little Ventilation volume in the kitchens and the bathrooms, and bad air quality in the living rooms and the bedrooms.

\subsection{Natural Ventilation Can Not Meet the Requirements of Indoor Ventilation}

In the absence of mechanical ventilation equipment, to eliminate the indoor waste heat and residual moisture, residents should consider the natural ventilation preferentially. There are two ways of natural ventilation include opening the windows or not, which is the common way for the ordinary residential to used ventilation In the past as well as present.

\subsubsection{Penetration}

In some cases when the residents need conditioned air , in order to reduce interior energy losses the residents need to close all the doors and windows. They can get fresh outdoor air by natural ventilation, relying on the osmosis affected by the wind pressure and hot press. But with the gradually increased level of building energy conservation, the tightness of the residential doors and windows are getting better and better. And with the deepening of building energy conservation, It has become increasingly impossible to achieve indoor ventilation by improving the building structure.

\subsubsection{Ventilation}

Opening windows is the most common natural ventilation pattern when the indoor air is difficult to diffuse and eliminate because of its concentrated heat and moisture quantity. But there are several obvious disadvantages, including that the ventilation volume is not easy to control, stability and uniformity of the indoor climate cannot be guaranteed, and it is affected by seasonal and climatic factors. Especially in the north, the designer will consider various forms of structure in order to meet the greatest effect of natural ventilation when doing architectural design of residential. But in reality, some residences can indeed reach a ventilation rate that is more than 10 times an hour. This might only bring good effect for part of the rooms to eliminate the residual heat and ventilation wet, but other important rooms may be not be effectively ventilated because of the building structure .

Air organization is uncontrollable when the windows are opening for natural ventilation. Disorder airflow can bring the peculiar smell from the bathroom and kitchen into the living room and bedroom 
with a lot of dust. It not only affects the indoor cleaning and sanitation, but also cannot avoid the outdoor noise pollution. For the high-rise residential, due to the effect of hot pressing, it is not effective to open the windows to introduce outdoor fresh air which can let the lower air in and aggravate pollution. In addition, the discontinuity of natural ventilation sometimes will cause greater pollution in the room. A survey about switch window on city residents shows that residents typically conduct intermittent operation, which means that someone would make the window open for a period of time after the closure. This approach is very effective for intermittent pollution, such as smoking pollution, but for continuous pollution problems, such as formaldehyde pollution, the effect is not obvious in this way.

Finally, window ventilation can bring serious noise pollution in some places. Because of the noise pollution in the vicinity of the traffic trunk road, this method cannot be used to achieve indoor ventilation. In addition, the noise pollution caused by the window ventilation from the neighborhood will also interfere and affect the normal life. Therefore, opening the window is not an ideal way for residential ventilation and in the north and other cold regions, the winter window will cause a lot of energy waste.

\subsection{The Necessity of Mechanical Ventilation for Residential Buildings}

With the change of lifestyles, increasing popularity of air conditioning, and the improving doors and windows sealing performance, relying on natural ventilation cannot satisfy the resident requirements for air quality. Therefore, it is more and more necessary to maintain good indoor air quality by using organized ventilation. Indoor ventilation is mainly in order to exclude harmful substances produced by human activities, by the indoor furniture and decoration materials emit toxic chemicals. At the same time, indoor thermal and moisture load is resolved by the air conditioning. According to relevant research reports at home and abroad, indoor pollutants were found to be about more than 300 different kinds. Pollutants produced by human activities are shown in table 2 .

Table 1 Pollutants produced by human activities

\begin{tabular}{cc}
\hline Life behavior & Pollutants \\
\hline Human activities & Vapor,Heat,Dust,Bacteria,CO \\
Smoking & Dust,Stimulants,CO,NO \\
Work & Dust,Solvent vapor \\
House cleaning & Dust,Bacteria \\
\hline
\end{tabular}

\section{Improvement of Traditional Residential Ventilation Method}

To sum up, mechanical ventilation is a suitable method for solving residential interior ventilation. With the development of building energy-saving technology, the tightness of residential gets better and better. Natural ventilation has been unable to meet the requirements of indoor air quality. According to the law of the development of Foreign Architectural Science, mechanical ventilation or combined natural and mechanical ventilation will become the main means to solve the indoor air quality.

\subsection{Residential Mechanical Ventilation Mode}

Generally, residential mechanical ventilation should be considered in conjunction with the bathroom exhaust. Kitchen hood exhaust and wind up system is best considered separately and the design of the ventilation system in the room should not be combined. Range hood is used just when cooking; air Volume of the Range hood is hard to balance with the air Volume of residential.

\subsubsection{Natural Ventilation and Mechanical Ventilation System}

The work flow of the mechanical room ventilation by this way is fresh air enters the room from the air intake in the living room and the bedroom. The dirty air is pumped from the toilet. The air inlet of natural ventilation should be installed in the bedroom and the living room outside the window or wall. And it has the function of adjusting the area of the air inlet. Bathroom exhaust fan exhaust air volume required to meet the bathroom itself and the number of ventilation times and the burden of the bedroom and the living room ventilation. When the room need ventilation, open the inlet valve and the bathroom exhaust fan in the room, this time, the room and the bathroom are in slight negative 
pressure, fresh outdoor air through the bedroom door to flow through the bathroom door or louvers, exhaust fan discharge through to the outdoors. It will adjust the inlet and outlet of the size of the concentration of carbon dioxide in the room according to carbon dioxide detector inside the bedroom automatically, so as to control the ventilation quantity. It will avoid the heat loss caused by excessive air flow, in the premise of meeting the requirements of ventilation. Bathroom and toilet mechanical exhaust air system not only can be designed into a horizontal type independent system, it can also be designed into a common vertical duct system (especially for high-rise buildings), at the top of the vertical channel best installation of roof exhaust fan, air households connected by vertical total row volume multiplied by 0.8.A double-speed roof fan which has score of $100 \%$ and $50 \%$, timely controlled by the property management department. The natural ventilation, mechanical ventilation system is very simple system without having to install the indoor air duct. Mechanical ventilation system is in a small negative pressure inside the room, the dust of the outdoor air will enter the room through the window.

\subsubsection{Mechanical Inlet and Exhaust System with Energy Recovery Function}

Mechanical intake and exhaust system with energy recovery function is composed of full heat exchanger, air inlet, exhaust fan, flexible connection pipe, inlet and outlet. The main operation principle is that in winter, the outdoor fresh air is heated by the waste heat from the exhaust air of the room through the full heat exchanger and subsequently be supplied to room. In summer, cold energy from air conditioned room will cool outdoor fresh air through the heat exchanger, and then the cooling air will be sent to room for the residents to use. This system can usually recycle $75 \%$ of the exhaust energy, so as to achieve the purpose of energy saving. In addition, its advantage is that the air supply is slightly larger than the air volume, so that the room is in a positive pressure state. But this mechanical system must be installed horizontally. Full heat exchanger with inlet and exhaust fan can be installed in the bathroom ceiling or balcony. Pipes may pass through the room, and it needs to be decorated by adopting local drop ceiling.

\section{Summary}

Apartment's mechanical ventilation has been widely used in Europe and Japan and other developed countries in residential apartments and villas, as China's economy continues to develop, people's living standards improve, people on indoor air quality requirements are also increasing. Natural ventilation due to various conditions and chamber design, reliability is low, can not meet the comprehensive residential ventilation requirements. Therefore, the use of the room organized mechanical ventilation is imperative.

\section{References}

[1]. Laverge J, Van Den Bossche N, Heijmans N, et al. Energy saving potential and repercussions on indoor air quality of demand controlled residential ventilation strategies[J]. Building and Environment, 2011, 46(7): 1497-1503.

[2]. Dorer V, Breer D. Residential mechanical ventilation systems: performance criteria and evaluations[J]. Energy and Buildings, 1998, 27(3): 247-255.

[3]. Russell M, Sherman M, Rudd A. Review of residential ventilation technologies[J]. Hvac\&R Research, 2007, 13(2): 325-348.

[4]. Dorer V, Breer D. Residential mechanical ventilation systems: performance criteria and evaluations[J]. Energy and Buildings, 1998, 27(3): 247-255. 